\title{
Integração ensino-serviço na formação de residentes multiprofissionais de saúde: concepção de docentes
}

\author{
Integration between teaching and health services in academic training for multi-professional health residents: \\ the professors' conception
}

Integración enseñanza-servicio en la formación de residentes multiprofesionales de salud: concepción de maestros

\author{
Amanda de Lemos Mello'; Marlene Gomes Terra"; Elisabeta Albertina Nietsche ${ }^{\text {III }}$
}

\begin{abstract}
RESUMO
Objetivo: analisar a concepção dos docentes de um Programa de Residência Multiprofissional em Saúde acerca da integração ensino-serviço na formação dos residentes. Método: pesquisa qualitativa realizado com 13 docentes envolvidos em ações de ensino do referido Programa, no período de março a junho de 2015, no sul do Brasil. Os dados foram coletados, após aprovação por Comitê de Ética em Pesquisa, por meio de entrevistas semiestruturadas e observações sistemáticas e, em seguida submetidos a análise temática. Resultados: a integração ensino-serviço foi compreendida a partir da práxis para a construção do conhecimento, apresentando-se como uma estratégia para aprendizagem significativa. Conclusão: os docentes, ao conceberem a integração ensino-serviço como uma estratégia que possibilita a práxis para a construção do (re)conhecimento, vislumbraram um movimento dialético, de alternância entre a prática e a teoria.

Descritores: Capacitação de recursos humanos em saúde; internato não médico; serviços de integração docente-assistencial; pesquisa qualitativa.
\end{abstract}

\begin{abstract}
Objective: to examine the teachers' conception of a multi-professional health residency program as to integration between teaching and services in the training given to residents. Method: this qualitative study was conducted, from March to June 2015, in southern Brazil, with 13 professors involved in teaching actions on the program. After approval by the research ethics committee, data were collected by semi-structured interviews and systematic observations, and then subjected to thematic analysis. Results: integration between teaching and services was understood as fostering praxis for the construction of knowledge, and constituted a strategy for meaningful learning. Conclusion: when conceiving integration between teaching and services as a strategy that allows praxis for building recognition and knowledge, professors envisaged a dialectical movement alternating between practice and theory.
\end{abstract}

Descriptors: Health human resource training; internship no medical; teaching care integration services; qualitative research.

\section{RESUMEN}

Objetivo: analizar la concepción de los maestros de un Programa de Residencia Multiprofesional en Salud acerca de la integración enseñanza-servicio en la formación de los residentes. Método: investigación cualitativa realizada junto 13 maestros involucrados en acciones de enseñanza del referido Programa, en el período de marzo a junio de 2015, en el Sur de Brasil. Los datos se recolectaron, tras aprobación por el Comité de Ética en Investigación, por medio de entrevistas semiestructuradas y observaciones sistemáticas y, después, sometidos a análisis temáticos. Resultados: la integración enseñanza-servicio se comprendió a partir de la praxis para la construcción del conocimiento, presentándose como una estrategia para el aprendizaje significativo. Conclusión: los maestros, al concebir la integración enseñanza-servicio como una estrategia que posibilita la praxis para la construcción del (re)conocimiento, vislumbraron un movimiento dialéctico de alternancia entre la práctica y la teoría. Descriptores: Capacitación de recursos humanos en salud; internato no medico; servicios de integración docente asistencial; investigación cualitativa.

\section{INTRODUÇÃO}

Os Programas de Residência Multiprofissional em Saúde (RMS), criados a partir da promulgação da Lei $n^{\circ} 11.129$ de 2005, abrangem as diversas profissões da área da saúde e orientam-se pelos princípios e diretrizes do Sistema Único de Saúde (SUS), conforme as realidades e necessidades locais e regionais ${ }^{1}$. A RMS permite, por meio da educação permanente em saúde (EPS), o envolvimento dos profissionais em formação com os trabalhadores do serviço, integrando o saber científico, o teórico e o prático².

'Enfermeira. Mestre. Aluna do Curso de Doutorado, Universidade Federal de Santa Maria. Brasil. E-mail: amandamello6@yahoo.com "Enfermeira. Doutora. Professora Associada, Universidade Federal de Santa Maria. Brasil. E-mail: martesm@hotmail.com.br

I'Enfermeira. Doutora. Professora Titular, Universidade Federal de Santa Maria. Brasil. E-mail: eanietsche@gmail.com

vagradecimento à Coordenação e Aperfeiçoamento de Pessoal de Nível Superior - Brasil pela concessão da Bolsa Demanda Social à dissertação de mestrado Integração ensino-serviço na formação de residentes multiprofissionais em saúde na perspectiva do docente que resultou neste artigo. Código de Financiamento 001. 
A inserção nas realidades práticas dos serviços públicos de saúde, proporcionado por esta modalidade, tende a fomentar a integração ensino-serviço, considerada como um trabalho coletivo, pactuado e integrado entre os profissionais em formação, docentes, trabalhadores dos serviços e gestores ${ }^{3}$. Nessas interações, todos os sujeitos delinearam um papel-chave, o do facilitador. Essa figura atribuída à ação dos docentes e dos profissionais dos serviços é correspondente ao papel de orientação, motivação e construção coletiva do conhecimento com a integração de saberes ${ }^{4}$.

A partir dessas reflexões questiona-se: como os docentes de um Programa de RMS concebem a integração ensinoserviço? E, assim, objetivou-se analisar a concepção dos docentes de um Programa de RMS acerca da integração ensinoserviço na formação dos residentes.

\section{REVISÃO DE LITERATURA}

A integração ensino-serviço na formação em saúde oportuniza uma aprendizagem próxima à realidade de saúde das pessoas e do SUS, que corresponda às necessidades concretas de ambos ${ }^{4,5}$. A residência pode ser considerada como espaço de EPS, de construção da identidade profissional e de cidadania, nos quais os profissionais do serviço, docentes, usuários e os estudantes vão construindo e estabelecendo seus papéis sociais na confluência de seus saberes, modos de ser e de ver o mundo 6 .

Considerando a perspectiva da integração ensino-serviço, essa pode ser uma estratégia fundamental para a consolidação dos serviços de saúde ${ }^{7}$. Para tanto, reconhece-se que há limitações que abarcam a realidade dessa nas RMS, como a falta de trabalhadores dos diferentes núcleos nos serviços de saúde e a provisoriedade dos residentes. Mas, ao mesmo tempo há diversas contribuições aos serviços de saúde e a atenção aos usuários ${ }^{5}$.

A partir desse eixo orientador e estruturante dos programas de formação nos serviços, as RMS podem ser consideradas como um espaço para o desenvolvimento e de (trans)formação para trabalhadores da saúde (inseridos na interseção ensino e serviço) articulado como dispositivo da educação permanente ${ }^{2}$.

\section{METODOLOGIA}

Estudo qualitativo ${ }^{8}$, realizado em uma RMS, do Estado do Rio Grande do Sul, Brasil. Participaram do estudo os docentes de uma universidade pública, selecionados a partir dos seguintes critérios de inclusão: ser docente do quadro efetivo vinculado à universidade e estar atuando em uma das seis áreas de concentração do Programa (crônicodegenerativo, materno-infantil, onco-hematologia, atenção básica/saúde da família, vigilância em saúde e saúde mental) há mais de um ano, no período da coleta de dados, pois esses teriam uma compreensão melhor da realidade assim como da formação dos residentes, encontrando-se ambientado com as práticas educativas. E, os de exclusão: aqueles que estivessem em licença para tratamento à saúde, licença maternidade ou paternidade ou em férias no período da coleta de dados.

O total de docentes integrantes da RMS eram 25, destes, 17 atendiam aos critérios estabelecidos. Dessa forma, buscou-se uma representação mínima de cada categoria profissional e área de concentração, sendo selecionados por um sorteio. Considerou-se importante a participação de todas as categorias profissionais, uma vez que a multiprofissionalidade é uma das principais propostas dos Programas de RMS. Sendo assim, participaram 13 docentes (homens e mulheres), sendo que o fechamento das coletas aconteceu por redundância de informações ${ }^{8}$.

A coleta de dados ocorreu de março a junho de 2015 por meio de entrevistas semiestruturadas. Estas foram realizadas em locais e horários escolhidos pelos participantes e ocorreram após a leitura do Termo de Consentimento Livre e Esclarecido. As entrevistas tiveram duração de aproximadamente de 40 minutos e iniciaram com a questão: o que você compreende como integração ensino-serviço? Com o consentimento dos participantes, as entrevistas foram gravadas e, após, foram transcritas na íntegra pela pesquisadora principal.

Na sequência, os dados foram submetidos à análise temática ${ }^{8}$, realizada em três etapas: ordenação dos dados, que correspondeu a transcrição e organização das entrevistas; classificação dos dados, que foram realizadas as leituras ordenadas e exaustivas dos dados. E a análise dos dados, a qual correspondeu à formação das categorias temáticas. As unidades de sentido orientaram a identificação de duas categorias temáticas: integração ensino-serviço vista a partir da práxis para a construção do conhecimento, e integração ensino-serviço: estratégia para aprendizagem significativa.

Os participantes são mencionados no texto com a letra $D$ de docentes, seguida de um número arábico de D1 a D13, resguardando-se sua identificação. Em todas as etapas do estudo os aspectos éticos foram preservados e respeitados, conforme a Resolução no 466/12 do Conselho Nacional da Saúde sobre pesquisas que envolvem seres humanos. O projeto de estudo foi encaminhado ao Comitê de Ética em Pesquisa, sendo aprovado sob o Parecer $\mathrm{n}$ o 932.528 e CAEE: 40246414.4.0000.5346. 


\section{RESULTADOS E DISCUSSÃo}

\section{Integração ensino-serviço vista a partir da práxis para a construção do conhecimento}

A integração ensino-serviço ao ser concebida como uma práxis educativa, torna-se um elemento para/ou o próprio processo de construção do conhecimento que (re)cria as condições para a transformação do mundo do trabalho, determinando finalidades e guiando as ações educativas para o encontro com o coletivo. Assim, no contexto da formação dos residentes, considera-se a educação e a assistência em saúde como dois aspectos indissociáveis de um mesmo processo como expressam os docentes participantes do estudo:

A integração ensino-serviço é justamente trazer para dentro dessas discussões que nós fizemos, aqui na Residência, que traz elementos teóricos, mas trazer muito da vivência desses alunos no serviço. (D3)

Temos tantas possibilidades de intervenções por estar no serviço. É bem essa minha perspectiva de integração na formação profissional: fazer esse elo com a formação do aluno e o trabalho. (D13)

A integração entre o ensino e o serviço, ao ser entendida como algo não estático, caracteriza-se como uma práxis que advém de um contínuo movimento de percepção, participação, ação-reflexão, direcionado por um projeto político e histórico em seus momentos de ação ${ }^{9}$. Considerando-a como uma prática vinculada à teoria, que requer um constante vai e vem de um plano ao outro, sendo ativa, flexível e criadora ao longo do processo educativo, expressando a complementaridade entre a teoria e a prática. O movimento de alternância entre esses eixos, possibilitada pela RMS, enfatiza a importância de ir além da visão dicotômica teoria/prática e criar mecanismos que auxiliem os docentes a potencializar a construção coletiva de novos saberes ${ }^{10}$.

Somando-se a isto, a partir da imersão do residente nas práticas de saúde, há a possibilidade de trabalho com diversos núcleos profissionais, sendo fundamental para a construção do conhecimento a partir da práxis grupal ${ }^{11}$. Esses espaços de encontro, como as tutorias de campo e de núcleo, preceptorias, discussões de casos e demais atividades coletivas, tendem a potencializar as ações de integração ensino-serviço por meio da problematização entre os diferentes atores, frente as suas práticas profissionais nos distintos cenários de atuação ${ }^{12}$.

Entretanto, a busca pela participação coletiva, com vistas à práxis da construção do conhecimento, necessita ser contínua e implica envolvimento, compromisso, troca, compartilhamento entre os diversos atores que participam ativamente dessa formação. Assim, a práxis educativa é o desvelamento da realidade que cerca a pessoa, seja através de um ato individual ou coletivo, em que os conteúdos, são guiados pelas necessidades das pessoas, pelos interesses próprios com participação efetiva e ação refletida de todos os envolvidos nesta situação ${ }^{9}$. Essa práxis efetiva-se na açãoreflexão-ação mediatizada pelo olhar e agir crítico e criativo:

\section{A Residência é a transformação dessa realidade, é o confronto com o gestor, com o usuário, é esse enfrentamento do drama cotidiano de, às vezes, você não ter material, não ter o equipamento para o atendimento e buscar soluções criativas [ ... ]. Então, é uma complexidade dada no cotidiano, é construir redes, é fazer pontes. (D1) \\ É você conseguir inserir esse estudante em um campo de trabalho, aonde ele vai, por sua própria participação, ganhar conhecimento e, nesse momento, fazer a troca pela de experiência [ ... ]. (D5)}

Para a efetivação da práxis educativa, de acordo com o requerido pela RMS, a ação dos residentes nos serviços de saúde pode ser desencadeada como dispositivos para a análise das práticas reais de saúde, sendo constituído como um espaço intercessor para o desenvolvimento das ações de EPS². E, para o desenvolvimento da mesma na lógica de uma práxis para a construção do conhecimento há a necessidade de efetivar a integração entre a formação, o desenvolvimento docente, a gestão e as equipes de saúde visando fortalecer o papel de cada indivíduo no desenvolvimento teórico e prático.

A partir de uma participação efetiva, questionadora, crítica e ética frente ao desenvolvimento do processo formativo, em que o estudante aprende não apenas por aprender ou para se adaptar à realidade posta, mas, sobretudo, para intervir sobre ela, transformando-a e recriando-a ${ }^{13}$.

\section{Integração ensino-serviço: estratégia para aprendizagem significativa}

A partir do contato vivenciado pelos docentes e residentes nos serviços de saúde é propiciada uma reflexão crítica ao vivido no cotidiano das práticas, além de investigar e instigar a própria prática configurando um novo saber fazer, um novo modo de conhecer e aprender. Na aprendizagem cotidiana, a integração ensino-serviço pode ser desenvolvida a fim de compreender as complexidades e as intersubjetividades das práticas de cuidado:

Eu vou trabalhar com a característica daquele sujeito que está para além daquela literatura e que está hoje no cotidiano daquele serviço [...] Quer dizer em qual lugar está acontecendo isso para que eu possa entender? Isso é integração ensino-serviço. (D1) 
É reinventar formas de cuidado, é reinventar formas de aprender a aprender. E aprender cotidianamente com os diferentes sujeitos nas complexidades, nas subjetividades, nas intersubjetividades. É a aprender a reinventar soluções para a vida cotidiana e também a aprender a fazer novas perguntas. (D10)

A integração ensino-serviço pode ser concebida, por um lado, como uma estratégia de reorientação da formação, na medida em que proporciona aprendizagens significativas e, por outro, como um mecanismo para potencializações e melhorias das ações de cuidado em saúde, por meio de um espaço de troca entre o estudante e o profissional ${ }^{14}$. A aprendizagem significativa, desencadeia as experiências de vida das pessoas, além de interrogar e problematizar a partir de uma relação dialógica de ensinar e aprender ${ }^{15-17}$. Além disso, implica a conexão ou vinculação do que o estudante sabe com os conhecimentos novos, quer dizer, o antigo com o novo.

A integração ensino-serviço vista a partir da aprendizagem significativa seria como um elemento em si mesmo constitutivo de uma nova maneira de pensar a formação. Entretanto, sinaliza-se que não se trata de transformar o espaço dos serviços e comunidade em extensões dos hospitais e demais serviços de saúde. Mas, de construir espaços de aprendizagem com a incorporação de docentes e estudantes à produção de serviços em cenários reais ${ }^{7}$.

Assim, os profissionais com diferentes formações na saúde, dispostos a transitar entre as áreas específicas de formação, articulam seu saber específico com o dos outros na organização do trabalho e isto é o que possibilita tanto compartilhar as ações como delegar atividades a outros profissionais, nos moldes de uma prática colaborativa ${ }^{18}$. Esse movimento, por sua vez, tende a aumentar a resolubilidade dos serviços e a qualidade da atenção à saúde. Corroborando esses aspectos, os docentes compreendem, de um modo geral, a integração ensino-serviço como um processo complexo e fundamental para a formação dos residentes, a partir da integração e da efetivação das políticas públicas nos serviços de saúde:

É integração. Ou seja, é aquilo que está na Lei 8080/90, de que o serviço público, os serviços de saúde, não só públicos, são espaços naturais, reais, para se aprender praticar, para fazer saúde. (D6)

[...] é a inserção desse profissional no serviço público, então a amplitude é maior nesse entendimento sobre a necessidade de formar um profissional integrado à realidade. (D12)

A relação do ensino com o mundo real do trabalho, como um movimento articulador dos contextos da universidade com o do serviço, aparentemente desconectados, busca superar os velhos modelos de ensino incapazes de cumprir o seu papel de formação de indivíduos capacitados para responder às necessidades da população de forma qualificada ${ }^{3}$. As RMS se apresentam como uma importante estratégia para viabilizar a integração ensino-serviço, a fim de repensar o processo de produção de saúde, por meio da formação de sujeitos críticos e de criação de espaços de representação profissional e movimentos sociais para o processo de construção do SUS 5 .

A proposta dessa integração amplia espaços de discussão para uma produção cooperativa, coletiva, integrada, sendo que os docentes realizam papel de mediadores, oportunizando o diálogo e instigando os residentes. Para isso, enfatiza-se a importância do pensamento crítico na formação do profissional de nível superior, com estratégias de ensino que possibilitem o residente a aprender, questionar e refletir.

O movimento dialético proporcionado pelas RMS, de ir e vir entre a prática e a teoria, entre a construção e a reconstrução do conhecimento, por meio da aprendizagem significativa, possibilita aos profissionais da saúde a compreenderem o seu lugar na assistência ao usuário e, principalmente, na efetivação do requerido pelo SUS. E, nessa linha de pensamento, enfatiza-se a importância de construir um conhecimento com o outro, a partir de uma cultura que permita ao ser humano compreender sua condição humana e ajudá-lo a viver, favorecendo, assim, um modo de pensar aberto e livre, ou seja, um ensino educativo, cuja missão do docente e dos demais implicados nessa formação não é transmitir um simples saber ${ }^{19}$.

\section{CONCLUSÃO}

Os docentes, ao conceberem a integração ensino-serviço como uma estratégia que possibilita a práxis para a construção do (re)conhecimento, vislumbraram um movimento dialético, de alternância entre a prática e a teoria. Quanto à concepção dos docentes acerca da integração ensino-serviço, vista como uma estratégia para a aprendizagem significativa, percebeu-se que o contato vivenciado nos serviços de saúde proporciona uma reflexão crítica ao vivido no cotidiano das práticas, além de investigar e instigar a própria prática, tanto do docente quanto do residente, configurando um novo saber fazer, um novo modo de conhecer e aprender a ser e fazer.

Reconhece-se que esta pesquisa, limita-se por ser um estudo local, no entanto espera-se ela presente estimule outras reflexões a respeito do tema e origine novos estudos, em busca de práticas pedagógicas corresponsáveis, com vistas a qualificar o ensino e a colaboração interprofissional, de acordo com as reais necessidades dos serviços de saúde. 


\section{REFERÊNCIAS}

1. Governo Federal (Br). Lei $n^{\circ} 11.129,30$ de junho de 2005. Institui o Programa Nacional de Inclusão de Jovens - Projovem; cria o Conselho Nacional da Juventude (CNJ) e a Secretaria Nacional da Juventude; altera as Leis no 10.683, de 28 de maio de 2003, e 10.429, de 24 de abril de 2002; e dá outras providências. Brasília (DF): Senado Federal; 2005.

2. Silva CT, Terra MG, Kruse MHL, Camponogara S, Xavier MS. Multi-professional residency as an intercessor for continuing education in health. Texto \& contexto enferm. [Internet], 2016 [cited 2018 Sep 26]; 25(1):1-9. DOI: http://dx.doi.org/10.1590/0104-0707201600002760014

3. Albuquerque VS, Gomes AP, Rezende CHA, Sampaio MX, Dias OV, Lugarinho RM. Service-learning in the context of the changes in the undergraduate education of health professionals. Rev. bras. educ. méd. [Internet], 2008 [cited 2018 Sep 25]; 32(3):35662. DOI: http://dx.doi.org/10.1590/S0100-55022008000300010

4. Brehmer LCF, Ramos FRS. Experiences of teaching-service integration in the process of professional development in health: an integrative review. Rev. eletrônica enferm. [Internet], 2014 [cited 2018 Sep 30]; 16(1):228-37. DOI: http://dx.doi.org/10.5216/ree.v16i1.20132

5. Mello AL, Terra MG, Nietsche EA, Siqueira DF, Canabarro JL, Arnemann CT. Training of multiprofessional residents in health: limits and contributions for teaching-service integration. Rev. enferm. Cent.-Oeste Min. [Internet], 2018 [cited 2018 Sep 30]; 8(1):1-10. DOI: http://dx.doi.org/10.19175/recom.v8i0.2567

6. Cezario JEP, Daher DV, Nolasco MFS. Program of Education through Work (PET) in Healthcare: linkage between qualification and integration of teaching and work. Rev. enferm. UERJ. [Internet], 2015 [cited 2018 Sep 30]; 23(5):644-8. DOI: http://dx.doi.org/10.12957/reuerj.2015.7979

7. Finkler M, Caetano JC, Ramos FRS. Teaching-service integration in the change process in Dentistry training. Interface comun. saúde educ. [Internet], 2011 [cited 2018 Sep 29]; 15(39):1053-67. DOI: http://dx.doi.org/10.1590/S1414-32832011005000023

8. Nascimento LCN, Souza TV, Oliveira ICS, Moraes JRMM, Aguiar RCB, Silva LF. Theoretical saturation in qualitative research: an experience report in interview with schoolchildren. Rev. bras. enferm. (Online) [Internet], 2018 [cited 2018 Sep 30]; 71(1):22833. DOI: http://dx.doi.org/10.1590/0034-7167-2016-0616

9. Vázquez AS. Filosofia da práxis. São Paulo: Expressão Popular; 2007.

10. Silva LAA, Arboit EL, Muller MP, Dalmolin IS, Sassi MM. Percepções de professores enfermeiros sobre a intersecção do trabalho assistencial e docente. Rev. enferm. UFSM. [Internet], 2014 [cited 2018 Sep 29], 4(2):313-22. DOI: http://dx.doi.org/10.5902/2179769210081

11. Vale EG, Pagliuca LMF, Quirino RHR. Knowledges and nursing praxis. Esc. Anna Nery Rev. Enferm. [Internet], 2009 [cited 2018 Sep 25]; 13(1):174-80. DOI: http://www.scielo.br/pdf/ean/v13n1/v13n1a24.pdf

12. Sales PRS, Marin MJS, Silva Filho CR. Academy-service integration in the training of nurses in a teaching hospital. Trab. educ. saúde. [Internet], 2015 [cited 2018 Sep 27]; 13(3):675-93. DOI: http://dx.doi.org/10.1590/1981-7746-sip00057

13. Cardoso DAS, Oliveira JM, Costa LMC. Reflective learning: the use of the collective portfolio. Rev. bras. educ. méd. [Internet], 2015 [cited 2018 Sep 26]; 39(3): 442-9. DOI: http://dx.doi.org/10.1590/1981-52712015v39n3e00012015

14. Alves LA, Freires IA, Braga CC, Castro RD. Service-learning integration process: successful experience in providing oral care to the community. ABCS health sci. [Internet], 2012 [cited 2018 Sep 26]; 16(2):235-8. DOI: http://dx.doi.org/10.4034/RBCS.2012.16.02.17

15. Flores GE. Educação permanente e aprendizagem significativa no contexto hospitalar: a perspectiva de enfermeiras educadoras [master thesis]. Porto Alegre (RS): Universidade Federal do Rio Grande do Sul; 2011.

16. Freire P. Pedagogia da autonomia: saberes necessários à prática educativa. 43a ed. Rio de Janeiro: Paz e Terra; 2011.

17. Ausubel DP. A aprendizagem significativa: a Teoria de David Ausubel. São Paulo: Moraes, 1982.

18. Franco TB, Chagas RC, Franco CM. Educação permanente como prática. In: Pinto S, Franco TB, Magalhães MG, Mendonça PEX, Guidoreni AS, Cruz KT, et al. Tecendo redes: os planos da educação, cuidado e gestão na construção do SUS; a experiência de Volta Redonda-RJ. São Paulo: Hucitec; 2012.

19. Morin E. Educação e complexidade: os sete saberes e outros ensaios. 4ạ ed. São Paulo: Cortez; 2002. 